productivity of the pharmaceutical industry, there have been many calls to speed up the process by 'repurposing' or 'repositioning' existing drugs. Unfortunately, that suggestion runs up against the same stumbling block faced by DCA: when drugs have gone off patent, it is difficult for a company to recoup the substantial investment required to test the drug in a new population of patients. Large pharmaceutical companies have expressed little interest in repurposing drugs - and at least two of the small companies that have tried have gone bankrupt.

The fundamental difficulty is that patent systems generally reward innovation, not development. Although it is possible to file a new 'method of use' patent to cover a repurposed drug, such patents are difficult, if not impossible, to enforce if a generic copy of the drug is already on the market.

Several solutions have been proposed, none of them perfect. One would be for the federal government to pay for clinical trials of repurposed drugs that - like DCA - lack intellectualproperty protection. This is an expensive proposition, however, and taxpayers might chafe at the notion of paying for trials that were previously the responsibility of the private sector.

Another possibility is to follow the path taken by the European Union, which allows an extra year of patent exclusivity if new uses are found for an approved drug. In the United States, a similar approach is already being used to encourage the testing of drugs for treating children: drug manufacturers get an extra six months of protection if they find a new paediatric use for their product. But this programme, although successful, comes with a trade-off: the drugs will remain free from generic competition, and therefore more expensive, for longer.

It is a difficult conundrum, but one that warrants serious thought and creativity from researchers, agencies and policy-makers alike. This is especially true as the US National Institutes of Health designs its Cures Acceleration Network, which was mandated in the recent health-care reform bill. Funds permitting, the network will try to repurpose drugs that pharmaceutical companies have abandoned. Such an initiative could cut down the time and expense needed to find new therapies, and those who would take up the effort deserve support.

\section{Singular vision}

\section{Reforms that could harmonize and enhance European research deserve support.}

$\mathrm{f}$ the plan set out on 11 May by Máire Geoghegan-Quinn, Europe's research commissioner, comes to fruition, the continent may finally realize its long-standing goal of a single market for science and technology. Her proposals aim to break down barriers to the transfer of knowledge and researchers, as well as to reform regulations that hamper high-tech businesses.

The plan has three key elements. It would create a single patent system that would grant companies protection for their inventions across all the European Union (EU) member states at once, removing the need to file separate patents in multiple countries. It would also set up an EU-wide pension scheme to make it easier for researchers to move around the continent. At present, pensions are not transferable from one member state to the next, which discourages movement. Finally, it would increase public procurement: directing the money that EU agencies spend on areas such as telecommunications, energyefficient buildings and computer software towards EU businesses, thereby spurring home-grown innovation rather than going after the cheapest price abroad.

None of these ideas is new, although in the past they have struggled to gain traction. The EU patent, for example, has previously proved too controversial in too many countries to make much headway, and the others have never had a sufficiently vigorous political champion.

This time things may be different. Geoghegan-Quinn was an experienced politician in her native Ireland before assuming her current post, and she has quickly earned a reputation for being nononsense, hard-driving and determined. And, for the first time, she is pushing an integrated plan. Instead of treating research (primarily in academic institutions) and innovation (primarily in the business world) in a piecemeal fashion, as the commission has done in the past, her plan treats them as an organic whole. The goal is to create a smooth flow from research discoveries to products and services on the market.

Geoghegan-Quinn says that the plan will refocus Europe's research efforts on a series of grand challenges facing the continent as a whole, such as climate change and an ageing population. New partnerships would bring together the EU, member states and public and private researchers to work on specific aspects of these grand challenges. For example, for the ageing-population challenge, these partnerships could work on tackling chronic diseases or on developing technologies to allow older people to stay in their homes for longer. Existing initiatives, such as Europe's multibil-
"The goal is to create a smooth flow from research discoveries to products and services on the market." lion-euro Framework programme for research, and the Joint Technology Initiative's public-private research partnerships, will also be integrated with the plan to avoid overlap.

Although there are some potential pitfalls in the plan - the pursuit of direct societal benefits and high-tech industrial growth cannot be allowed to undermine basic research, for example - it is on the right track. Geoghegan-Quinn's vision will come under scrutiny this autumn, when EU heads of state meet to discuss it in detail. The task now is to sustain political momentum, and to ensure that the necessary decisions are taken at that autumn summit. European research minsters should explicitly give their endorsement for moving this agenda forward when they next meet on 25 May.

Geoghegan-Quinn's reforms are especially important given Europe's current financial crisis. Budgetary pain is looming for everyone, so the kind of integration and coherence that Geoghegan-Quinn has outlined is essential for making the most effective use of the research money that scientists do have. 